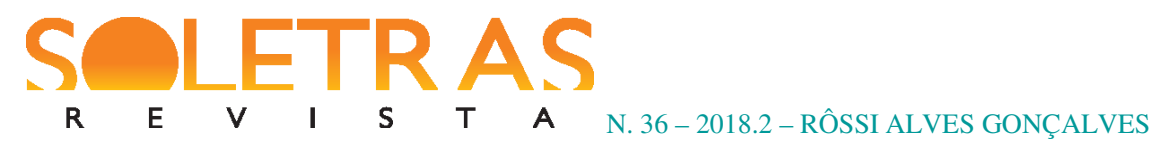

\title{
A cultura urbana periférica: silenciamentos e táticas
}

\author{
Rôssi Alves Gonçalves ${ }^{1}$ \\ Marildo José Nercolini ${ }^{2}$
}

Resumo: Neste artigo, analisamos duas manifestações fundamentais da arte urbana da cidade do Rio de Janeiro, entendendo-as como narrativas anticanônicas da cidade: as Rodas Culturais e os Bailes Funk, ambas produzidas por sujeitos advindos das periferias cariocas. Analisaremos as dificuldades impostas pelo poder público à realização destas intervenções, detectando e avaliando as táticas usadas por esses sujeitos para suplantar as dificuldades de se colocar em circulação sua arte. No Rio, o silenciamento dessas expressões se dá pela proibição dos Bailes Funk nas favelas e pela repressão às Rodas Culturais no espaço público. Entretanto, dado que o campo da cultura se apresenta como processo, tal situação de silenciamento não se fixa. Se há fronteiras simbólicas e reais restringindo o fazer artístico desses jovens, elas também produzem contranarrativas, em que ficam explícitas as inovadoras maneiras de criar arte em contexto de repressão e criminalização. A ação desses sujeitos periféricos tem trazido à cena cultural carioca novas formas de trocas, hibridismos e experimentações variadas que encontram nas quadras, ruas e praças um lugar de acolhimento. Palavras-chave: Arte urbana carioca. Narrativas. Repressão. Resistências.

Neste trabalho, partimos do pressuposto de que para entendermos de forma mais complexa e aprofundada as manifestações culturais precisamos analisá-las como práticas sociais, na linha de pensamento sugerida por Raymond Williams (2005). Isso significa não somente revelar seus componentes, dissecando-os e classificando-os, isolados de um contexto mais amplo, mas situar essas práticas, avaliar as condições em que são criadas e consumidas, considerando os embates, as negociações, apropriações e interconexões mais amplas no campo cultural. Ao discutirmos essas manifestações, seus processos de criação e circulação, pensamos a própria cultura em que se situam os sujeitos e suas produções. Afinal, é no campo da cultura que se concretizam essas práticas. Como afirma Williams (2005, p. 224),

[...] à medida que descobrimos a natureza de uma prática determinada, e a natureza da relação entre um projeto individual e uma modalidade coletiva,

\footnotetext{
${ }^{1}$ Doutora em Letras, na área de concentração Teoria Literária, pela Universidade Federal do Rio de Janeiro (UFRJ). Professora do Programa de Pós-Graduação stricto sensu em Cultura e Territorialidades - UFF. Tem Pós-Doutorado em Estudos Culturais, pelo PACC/UFRJ, RJ, RJ, Brasil. E-mail: rossialves14@ gmail.com.

${ }^{2}$ Professor Associado do Departamento de Estudos Culturais e Mídia e do Programa de Pós-Graduação em Cultura e Territorialidades (PPCULT) da Universidade Federal Fluminense. Doutor em Ciência da Literatura, na área de Literatura Comparada, pela UFRJ. Mestre em Sociologia pela UFRGS. No momento, vem desenvolvendo o projeto de pesquisa "Identidade, memória e territorialidade mediados pela música: os usos contemporâneos da música nas favelas do Rio de Janeiro”. Seus estudos, pesquisas e orientações focalizam estudos de cultura, em especial acultura urbana, música popular brasileira, pensamento latino-americano, tradução cultural, identidade, territorialidade e memória.
} 


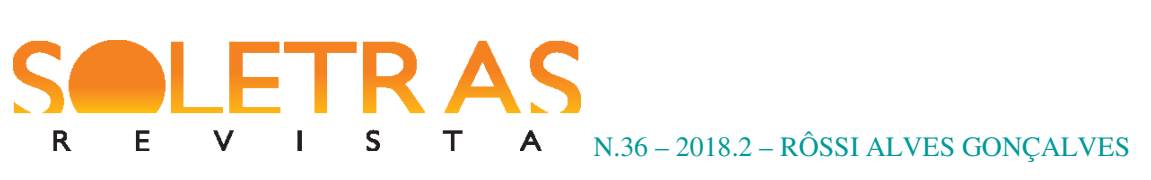

vemos que estamos analisando, como duas formas do mesmo processo, tanto sua composição ativa quanto as condições dessa composição, e em ambas as direções se trata de um complexo de relações extensivas e ativas.

Toda e qualquer produção artístico-cultural é engendrada dentro de uma cultura, nas conexões estabelecidas entre as diversas manifestações artísticas, nestes ambientes "entreculturais" vivenciados pelos sujeitos contemporâneos. É nesses entrecruzamentos, marcados por embates e negociações, que se constroem, atribuem e circulam sentidos e valores da vida social. Também é ali que os criadores surgem e é desses territórios que eles retiram os elementos e os dispositivos para criar, ao mesmo tempo bebendo nas fontes culturais e delas se colocando como artífices das mudanças. Afinal, como Clifford Geertz (1989, p. 4) preconizou, "o homem é um animal amarrado a teias de significados", mas "que ele mesmo teceu". Essas criações reforçam ou contestam sentidos e valores presentes, propõem novas rearticulações, sempre jogando com sentidos e valores sociais a partir dos contextos em que se vive, dos resquícios/vestígios do que se vive, buscando preservar o passado, com vistas a construções presentes e/ou futuras.

Partimos do entendimento dinâmico do termo cultura, na linha dos Estudos Culturais (com acentos britânico e latino-americano): um campo de luta em torno da significação do campo social, em que os sentidos em sociedade são definidos por relações de forças mutáveis e irregulares, processos no qual algumas produções são prestigiadas, enquanto outras são preteridas ou destronadas. Entre confrontos e negociações, a cultura se faz e refaz, processual e dinamicamente. Situar-se na cultura, já nos ensinavam os citados Williams e Geertz, nos leva a entender e "abarcar as relações interculturais", como recentemente enfatizou Néstor Garcia Canclini (2005, p. 48), como ações fundamentais para a compreensão mais ampla dos fenômenos culturais, em suas relações, articulações, práticas e manifestações.

Sendo assim, propomo-nos a analisar duas expressões da arte urbana contemporânea carioca que têm estado em evidência nos últimos anos: as Rodas Culturais e os Bailes Funk. Ambas são produzidas, sobretudo, por jovens das periferias do Rio de Janeiro, que enfrentam constantes dificuldades impostas pelo poder público à realização de suas intervenções culturais no espaço urbano da cidade. No Rio de Janeiro, o silenciamento destas expressões culturais se observa, dentre outros meios, na proibição dos bailes funk nas favelas e na repressão à ocupação do espaço público, no caso das Rodas Culturais. Em meio a embates e 


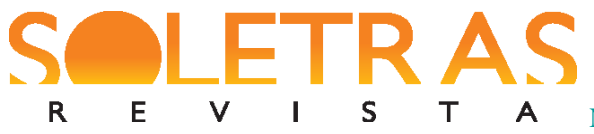

negociações, próprios dos processos culturais, tal situação de silenciamento, no entanto, não tem vingado: vive-se na cidade carioca um constante reordenamento dos espaços sociais, observado na criação e recriação de territórios, de alternativas e resistências à repressão.

Entende-se por arte urbana, comumente e em sentido estreito, a manifestação cultural realizada no espaço público ou em locais de fácil acesso, como os clubes de comunidades, por meio de equipamentos culturais que possibilitam a venda de ingressos a preços módicos. Por esse entendimento simplificado, a arte urbana seria a cultura que povoa a cidade e feita por seus habitantes, materializada nos espaços públicos, como ruas e praças; arte de rua, entendida como a que é realizada, independentemente do reconhecimento e apoio das instâncias hegemônicas de poder, por atores sociais expostos a algum grau de marginalização, seja por seu lugar de origem, pela cor, pela atividade profissional ou mesmo pela produção de eventos culturais ainda desconsiderados pela cultura hegemônica. Há, em especial, na cidade do Rio de Janeiro, manifestações culturais, como as rodas de samba, por exemplo, que ocorrem em ruas e já contam com certa legitimidade. Embora aconteçam também nos logradouros públicos, podem se sustentar economicamente a partir de casas de shows, teatros e espaços culturais onde têm aceitação.

Neste texto, trataremos mais especificamente de expressões como as Rodas Culturais originadas nas ruas e que nelas se mantêm pela falta de espaços outros em que possam se desenvolver - e os bailes Funk, espaços fundamentais, tanto para a criação e sedimentação da cultura funk quanto para a sociabilidade e diversão nas favelas e nos subúrbios cariocas, que constantemente têm sofrido processos de interdições e proibições, mas que, a duras penas, vêm resistindo.

Da Matta (1997), ao cotejar as categorias casa e rua, apresenta esta última como o espaço das impessoalidades, do perigo, da submissão às leis, local liminar, de luta, de astúcia. Nesse sentido, pensar a cultura urbana requer não perder de vista as ordens "regulatórias" deste espaço. Sendo assim, a arte ora examinada neste trabalho se vê submetida a todo tipo de sorte característica do espaço urbano, como instabilidades climáticas, repressão policial, brigas, atrasos, cancelamentos, improvisos, deslegitimação e silenciamento midiáticos etc.

\section{As falas rimadas das ruas}


A Roda cultural é uma manifestação que ocorre no espaço público e é realizada basicamente por jovens. Consiste em uma reunião de artistas, como grafiteiros, rappers, fotógrafos, MCs, malabaristas e performers. Essa atividade, aqui considerada para pensar resistências, acontece no Estado do Rio de Janeiro há quase dez anos. Teve início no bairro boêmio da Lapa, região central, frequentada por todo tipo de público e que possui íntima relação com o rep ${ }^{3}$, muito embora tenha se fixado no imaginário popular como lugar do samba.

A Lapa dos anos 2000 acolhia alguns pontos de encontro dos artistas e público de rep - ritmo e poesia. $\mathrm{O}$ fato de ser um ponto convergente para tantas pessoas ligadas ao gênero musical talvez se explique por ser um bairro central, de fácil acesso. É lá que se abriga a Sinuca da Lapa, bar emblemático para os rappers e público afim, e se localizava o CIC Centro Interativo de Circo, uma "escola" de rep que funcionava dentro do espaço cultural Fundição Progresso. Esses dois lugares povoam intensamente os relatos e documentos acerca do rep no estado do Rio de Janeiro, nos anos 2000.

Como aqui interessa investigar as Rodas Culturais, partimos de seu surgimento, após o fim do CIC, como visto, espaço de atividades do rep. Alguns dias da semana, artistas, produtores culturais e fãs de rep lá se encontravam, para debates, oficinas de rep, batalhas de rima, rodas de freestyle, saraus, shows etc. Muitos artistas da cena independente e que atualmente são conhecidos no Brasil e no exterior ali iniciaram ou desenvolveram suas obras, dentre eles, MCs Funkero, Marechal, Nissin Oriente, Dropê Comando Selva e Negra Rê.

O CIC funcionava à semelhança de uma escola aberta para o rep no Estado do Rio de Janeiro e com seu fechamento, ocasionado por um incêndio, os frequentadores passaram a se encontrar na rua, em frente à Fundição Progresso, sob os Arcos da Lapa, onde formavam rodas de rima. Como os encontros, mesmo na rua, continuaram constantes, teve-se a ideia de realizar aquela atividade em alguns bairros, onde os frequentadores - artistas e público moravam. Assim, surgiram, em dias variados da semana, eventos de rep pelas praças da cidade do Rio de Janeiro.

No princípio, os encontros tinham como atração maior as rodas de rima - círculos em que um MC rima e improvisa acompanhado de beatbox. Como eram regulares, em dias e

\footnotetext{
${ }^{3}$ Usaremos a forma aportuguesada rep, por ser defendida por artistas e simpatizantes do movimento.
} 
horários certos, as reuniões foram angariando público e se espalhando pela cidade e até para fora do Rio de Janeiro. Tornaram-se mais potentes, agregando diversas linguagens artísticas que podem ser exibidas nas praças e ruas sem a exigência de recursos sofisticados. Atualmente, há cerca de cem Rodas Culturais no Estado do Rio de Janeiro. Essa manifestação cultural pode ser encontrada em muitos outros estados do Brasil. Tal intervenção cultural constitui o que Fontes (2013) conceitua como "amabilidade urbana", isto é, a formação de uma rede de "hospitalidade, generosidade", de afetos tecidos pelo contato que a intervenção no espaço público cria. Ocupar as ruas e praças com arte é intervir na dinâmica da vida da cidade, recusar a individualização e a passividade diante das políticas impostas ao cidadão.

As Rodas Culturais reúnem centenas de pessoas por noite. E como há encontros regulares, o público do rep tem, diariamente, um evento para aproveitar. No entanto, embora as praças estejam sendo revitalizadas e os moradores desses bairros (que, em sua maioria, são desprovidos de lugares para exercício da arte), crianças, adultos, adolescentes, tenham a oportunidade de lazer e conhecimento da cultura hip hop, bem como de capacitação para a prática da rima, não há por parte do poder público apoio a esse tipo de evento. Luta-se diariamente pela autorização para manter a ocupação. Buscam-se documentos no Batalhão da Polícia Militar, explica-se à Guarda Municipal a natureza do evento, recorre-se à Secretaria de Cultura e a outras esferas em troca de liberação para manter a ocupação da rua. A experiência de luta e resistência é permanente.

Desde seu início, as Rodas Culturais configuram-se como atividades que buscam revitalizar praças e ruas abandonadas. Normalmente são escolhidos lugares que têm potencial para acolher o morador e as artes, mas que são subutilizados ou ocupados apenas por moradores em situação de rua. Assim, a Roda Cultural e a reunião que promove são recursos de valorização do bairro, estimulando a arte, chamando a atenção do prefeito e do comércio para novos significados para o espaço.

O verbo revitalizar, para a arte de rua, carrega, então, outros valores, muito distantes daquele de que se reveste a ação dos governantes. Nos últimos anos, a cidade do Rio de Janeiro sofreu intensa gentrificação, sob a denominação de revitalização. Diversas obras visando aos eventos esportivos reconfiguraram a cidade, chegando a apagar parte de sua memória. No entanto, o investimento das Rodas Culturais no espaço urbano é da contraordem: povoando, convidando o bairro a rimar, adotando afetivamente o lugar, 


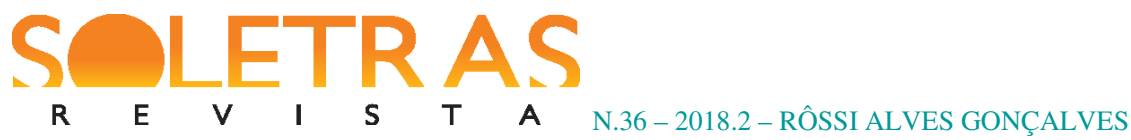

reinventa-se a rua no sentido muito semelhante ao que Harvey (2013) diz: o direito à cidade como direito de criar a cidade que se deseja e não só o de usufruir o que já existe. Sansão (2013, p.132), mencionando Borden, diz que:

[...] a apropriação não é o simples reuso de um espaço, mas o retrabalho criativo desse espaço-tempo. O processo de apropriação cotidiana de um espaço construído implica, portanto, certa desconstrução deste espaço, sua transformação criativa, e é aí que reside a essência da vida coletiva no meio urbano.

Assim, os organizadores de Rodas Culturais, bem como a comunidade da Roda, estão reconstruindo a cidade a seu modo e apropriando-se com mais vigor do espaço público. Esse evento cultural é, então, no sentido que Certeau propõe, uma "tática" usada contra o descaso público com um gênero musical subalternizado e com as ações de sujeitos da periferia:

\begin{abstract}
A ação calculada que é determinada pela ausência de um próprio. Então nenhuma delimitação de fora lhe fornece a condição de autonomia. A tática não tem por lugar senão o do outro. E por isso deve jogar com o terreno que lhe é imposto tal como organiza a lei de uma força estranha. Não tem meios para se manter em si mesma, à distância, numa posição recuada, de previsão e de convocação própria (CERTEAU,1998, p. 100).
\end{abstract}

Isto é, como esses eventos culturais realizam-se "no amor", ou seja, sem verba para custear as ações; com participações de artistas que não cobram cachê; sem aparelhagem de som própria (normalmente é emprestada) e com energia elétrica obtida por meio da "gambiarra", dentre tantas outras dificuldades resolvidas à base do imenso desejo de que a Roda aconteça, a despeito das instâncias de repressão, esta intervenção cultural exige dos participantes e dos envolvidos uma constante "prontidão de sentidos" (SANTOS, 2000). As adversidades são resolvidas conforme surgem e as pessoas envolvidas vão acumulando modos de resistências e formas de empoderamento que serão acionados numa situação de necessidade futura.

Dentre as táticas, a mais buscada pelos organizadores, em caso de repressão à Roda, em que esta fica proibida de ocorrer, é a denúncia nas redes sociais. Em forma de posts ou vídeos, expõe-se o embargo ao funcionamento das Rodas Culturais. Este recurso é bastante efetivo, no sentido de conseguir adesão de outras Rodas Culturais, do público e por provocar 


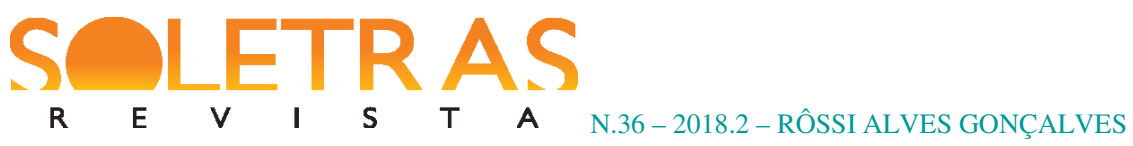

o debate sobre os percalços da arte urbana, conforme explica o texto de apresentação deste evento, na rede social Facebook, no qual centenas de pessoas confirmaram presença:

Infelizmente as rodas culturais voltaram a sofrer opressão e estão sendo CENSURADAS pela Polícia Militar de acontecer. Faremos uma roda cultural em frente à prefeitura para reivindicar nosso livre direito de manifestação e a lei do artista de rua para as rodas aconteceram (12/02/17). ${ }^{4}$

Diante das adversidades e impossibilidade de diálogo com os setores responsáveis pelo ordenamento público, denunciar e esbravejar são atitudes que funcionam também como meio de fazer as insatisfações, indiretamente, ecoarem nas instituições repressoras. Ou seja, há meios diferentes e propositivos que ajudam a reverberar a resistência. Roberto Machado (1979, p. XIV), na introdução à Microfísica do poder, aponta: "E como onde há poder, há resistência, não existe propriamente o lugar de resistência, mas pontos móveis e transitórios que também se distribuem por toda a estrutura social". A arte de rua no Brasil é instada, permanentemente, a encontrar lugares para reação.

Ocupar a rua/praça sem som, quando a Roda Cultural fica impedida de acontecer, é bastante comum. Dado que o som potente é um dos elementos de reclamação da vizinhança e logo relacionado pela polícia, é forma de resistência eficiente reunir o público e artistas no local, sem o som, e transformar aquele espaço em uma ágora contemporânea, com debates, propostas, rimas e outras formas de protesto.

Foram apontadas até agora táticas a fim de sensibilizar os órgãos públicos quanto à necessidade de se manter a ocupação das ruas com a Roda Cultural, porque o entendimento de tática como "arma dos fracos", instrumento possível no instante em que a luta exige atividade, é essencial para se compreender como sobrevive a arte urbana no Brasil. Porém, nessa arte de rua, em que o improviso é constante, há outros momentos em que esses meios de embate contra as estratégias dominantes são demandados.

Como já identificado, a Roda é sujeita a intempéries diversas. E para que a festa aconteça, exige-se dos produtores conhecimento de certos arranjos, gambiarras, sem os quais o evento não se realiza plenamente. Gambiarra, na acepção que Certeau (1998) é termo

\footnotetext{
${ }^{4}$ Ver https://www.facebook.com/events/632171286994047/.
} 
homólogo à "sucata": "golpes no terreno da ordem estabelecida", "invenções técnicas", "resistência moral", habilidade para lidar com o inesperado, com a escassez, com o duvidoso.

Como ocorre em espaços públicos, a energia para alimentar o som é ativada do poste mais próximo. Esse uso, em alguns eventos, é liberado pelas autoridades públicas. No entanto, em várias intervenções públicas, é comum não haver licença para tal utilização e uma série de transtornos ocorrer. Como são poucas as Rodas com gerador próprio, a gambiarra se configura alternativa bastante comum.

A falta de recurso próprio que sustente a ação muitas vezes é resolvida com o pedido de ajuda ao público, que doa quantias baixas, e com a "contribuição" dos ambulantes que trabalham no local. Assim, como em dias de Roda Cultural, a praça fica repleta de jovens que curtem rep e de outras pessoas que procuram lazer, ela se torna um bom lugar para o comércio de bebidas e alimentos. Dessa forma, diversos trabalhadores informais ocupam, com seus carrinhos, isopores e tabuleiros, o espaço da Roda. E há, em alguns eventos, uma taxa paga pelo ambulante aos organizadores da Roda, a fim de cobrir alguns custos do encontro. Entretanto, pelo que investigamos, essa taxa é mais sugerida do que obrigatória. Faz parte daqueles acordos que, sendo ou não cumpridos, não impedirão o trabalho de ambos os lados e nem irromperão em violência. São acordos de rua, firmados sob a compreensão de que um ajuda o outro, em um laço de fortalecimento que, mais do que a moeda de negociação, forma redes de resistência e proteção.

$\mathrm{Na}$ ausência de formatos mais acessíveis de organização e produção dos eventos nos espaços abertos, o que seria possível caso o poder público atendesse às reivindicações de artistas e produtores de cultura urbana, esses expedientes comuns - que operam entre o lícito e o ilícito - constroem a imagem do movimento, isto é, evidenciam os artifícios utilizados para a que a arte de rua resista.

\section{A fala bailada do funk}

Certamente, e sem medo de errar, podemos afirmar que o funk tem sido nas últimas décadas uma das principais manifestações da cultura urbana da cidade do Rio de Janeiro. A história do funk no Rio - desde os seus primórdios no final da década de 70 e início dos 80, 
passando pelo momento de consolidação nos anos $90^{5}$, chegando aos dias atuais - é marcada por muitos embates, proibições, tentativas de silenciamento, apropriações, mas também foi sendo construída por seus principais fomentadores - jovens artistas favelados - como maneira de se manifestar e de se serem aceitos como cidadãos.

A importância do funk como criação estética/artística híbrida tem papel fundamental no cotidiano das periferias do Rio de Janeiro. Pensamos aqui o estético imbricado na vida cotidiana (ESCOBAR, 2014), servindo como elemento aglutinador e forma de, ao mesmo tempo, construir e expressar o dia a dia desses agentes periféricos, suas lutas, desejos, autorrepresentação e valores. A música (no caso específico do funk) é instrumento privilegiado de trocas, diálogos e disputas no campo social, usada estrategicamente pelos agentes periféricos na construção de representações (individuais e coletivas), tendo em vista as formas de ser/estar no mundo com vez e voz próprias, possibilitando a construção/reconstrução dos espaços onde se vive e circula. Mesmo jovens que não criam funks, mas os reproduzem, cantando ou ouvindo, fazem-no porque se identificam com o ritmo e as letras. O funk é instrumento privilegiado de narração do espaço, de desejos e vivências do cotidiano do indivíduo e também instrumento usado por jovens favelados para serem respeitados e reconhecidos como sujeitos de cultura.

Os funkeiros, a partir de muitas mesclas e hibridações, foram criando uma linguagem musical/corporal em que produziam e faziam circular saberes de sua arte, como forma de resistir às discriminações sofridas e também como forma de re-existir, reinventando a si e o espaço onde vivem - a favela -, entrando na luta pela representação de suas individualidades e de seus locais, não mais vistos como falta, mas como potência. Criam uma arte crítica, no sentido dado por Mouffe (2007), isto é, arte que explicita, mantém e cria tensões, fomentando o dissenso, tornando visível e confrontando o consenso e suas muitas tentativas de obscurecer e silenciar o que não lhe é adequado.

Houve e ainda há um processo de criminalização do funk, sobretudo a partir dos anos 90. Como muito bem sintetiza Adriana Facina (2009, p.1),

Grito da favela, voz do morro cantando a liberdade, som da massa, o funk é um dos ritmos mais malditos da cultura popular brasileira. Seus detratores

\footnotetext{
5 Não vamos nos ater à história do funk, já sobejamente analisada. Ver para isso VIANNA (1988), HERSCHMANN (2000), ESSINGER (2005), LOPES (2010).
} 


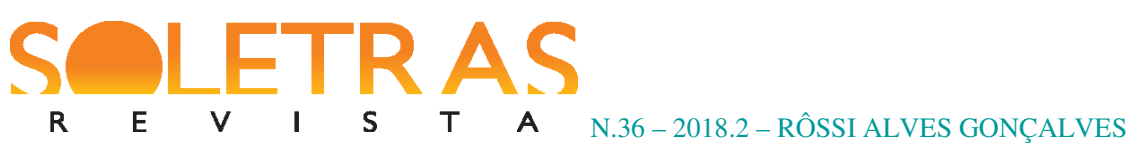

afirmam que o funk não é música, que seus cantores são desafinados, suas letras e melodias são pobres e simples cópias mal feitas de canções pop ou mesmo de cantigas tradicionais populares. Há ainda os que demonizam o batidão, associando-o à criminalidade, à violência urbana ou à dissolução moral. Ao criminalizarem o funk, e o estilo de vida daqueles que se identificam como funkeiros, os que hoje defendem sua proibição são os herdeiros históricos daqueles que perseguiam os batuques nas senzalas, nos fazendo ver, de modo contraditório, as potencialidades rebeldes do ritmo que vem das favelas.

No contexto da cultura funk, o baile ocupa um lugar estratégico, dentre outras razões, porque serve de instrumento fundamental à consolidação do funk carioca. É o espaço usado para que jovens artistas apresentem suas criações, tornando-as conhecidas do público e possibilitando sua circulação. A aceitação/sucesso de um funkeiro e suas canções passa pelo crivo do baile, espaço, portanto, também de legitimação desses sujeitos e de sua arte que, por esse crivo, podem mais facilmente circular em coletâneas, gravadas inicialmente de forma amadora, compartilhadas na Internet, em canais como o YouTube.

Cabe, também, destacar o baile funk como espaço de sociabilidade e diversão para esses jovens favelados. Muitas vezes e em muitas comunidades foi o único espaço de diversão para os jovens da periferia. Nele, os criadores se encontravam e compartilhavam, entre si e com o público, sua arte.

Segundo dados apresentados por Hermano Vianna (1990), em pesquisa realizada em 1987, havia cerca de seiscentos bailes funk por fim de semana no Rio de Janeiro, atraindo um público de mais ou menos um milhão de pessoas. De acordo com Vianna (1990, p. 244), “esses números colocam o baile funk como uma das diversões mais 'populares' da cidade. Só a praia parece atrair, com essa frequência, um público fiel”. Isso significa dizer ainda que o baile funk é (era) o "ganha pão" de muitos jovens e tinha importância econômica muito grande para as favelas onde eram realizados. MC Calazans, em entrevista ao jornalista André Balocco, de $O \mathrm{Dia}^{6}$, afirma que "o baile funk é uma invenção da favela para criar uma economia e gerar renda. É uma estrutura dentro de uma cultura de sobrevivência, diante da ausência do Estado e de políticas públicas", além de fortalecer economicamente a comunidade, possibilitando a ascensão social de jovens com poucas opções além da entrada

\footnotetext{
${ }^{6}$ Ver em http://odia.ig.com.br/noticia/riosemfronteiras/2013-08-19/extincao-dos-bailes-funk-deixou-9-mil-semtrabalho.html, acessado em 20/02/2017.
} 
no mundo do tráfico ou nas igrejas evangélicas. Para Calazans, "um moleque que era invisível, através do baile funk começa a ter uma existência social e cultural ali”.

Em sua dissertação de mestrado, Dennis Novaes analisa, no capítulo 1, alguns dos bailes funk cariocas mais representativos - bailes da Chatuba, do Mandela e da Providência, e, cabe acrescentar outro não analisado, o Baile do Chapéu Mangueira. Um dos mais emblemáticos é o Baile da Chatuba, considerado “o Maracanã do Funk". Novaes entrevistou DJ Byano, que comandou esse baile por 16 anos, realizado na quadra da comunidade, durante os fins de semana, reunindo "MCs, artistas, jogadores de futebol e alguns dos bandidos mais famosos do Rio de Janeiro, além, é claro, de milhares de funkeiros." Vindos de diversas localidades da cidade e às vezes do país, "geralmente em ônibus fretados que se apinhavam no pé do morro", Novaes (2016, p. 21) nos relata:

\begin{abstract}
Certa noite chegou-se ao número de 40 coletivos, enfileirados na estreita rua Maragogi que serve de acesso ao morro da Chatuba. Devido ao grande número de pessoas - em torno de 5 mil nas noites mais movimentadas espremidas num espaço tão pequeno, podia-se levar meia hora para percorrer os curtos 30 metros que separavam o palco do DJ e o banheiro. Além da arquibancada que ocupava uma lateral da quadra, metade do perímetro era cercada por um elevado de mais ou menos 3 metros de altura: era o camarote que abrigava as figuras ilustres que prestigiavam os bailes, fossem elas oriundas da televisão, dos campos de futebol, ou responsáveis pelo varejo local de substâncias ilícitas. Surgia assim o cenário para a consolidação do que viria a se tornar um dos maiores centros de produção e divulgação do funk carioca [...] (NOVAES, 2016, p. 21).
\end{abstract}

Ainda de acordo com Novaes, vários MCs fundamentais na história do funk carioca (por exemplo, Smith, Max, Frank, Tikão e Orelha) dele participaram e o baile da Chatuba foi decisivo para suas carreiras, pois "ter o seu funk consagrado nesse baile, era garantia de disseminação", pois "a consagração ali era considerada uma garantia de sua disseminação por grande parte dos bailes e rádios do Rio de Janeiro e do país" (NOVAES, 2016, p.22). Esse relato pode ser estendido a outros MCs e a muitos outros bailes funk, igualmente importantes na disseminação e a consolidação do funk carioca.

É importante se falar também sobre o Chapéu Mangueira, favela encravada no Morro do Leme, em plena Zona Sul carioca. Essa favela está fortemente envolvida na história do funk carioca e em seu processo de circulação para além dos morros e do subúrbio cariocas, atingindo o asfalto, e a consequente massificação do gênero, que se dá após os anos 90. Ali 


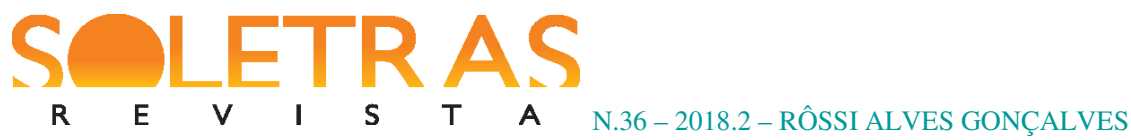

nessa comunidade acontecia um dos principais bailes funk da cidade e que começou a ser frequentado por jovens da Zona Sul, entre os anos de 1994 e 1995. É também naquela época que as leis de proibição ou cerceamento dos bailes funk pela primeira vez se configuram na cidade. Como nos lembra Adriana Facina (2009, p.4),

Em termos do ordenamento jurídico, a repressão ao funk no Rio de Janeiro tem como marco a CPI municipal do funk, ocorrida em 1995. Seu objetivo era investigar a suposta ligação do funk com o comércio varejista de drogas na cidade, sempre denominado de "tráfico" no discurso criminalizante. A CPI foi uma reação ao sucesso do baile no morro Chapéu Mangueira, na Zona Sul carioca, frequentado pela juventude de classe média do "asfalto" nos anos de 1994 e 1995. O baile terminou impedido de funcionar pelos poderes públicos, sob a alegação da venda de drogas e da ausência de tratamento acústico.

De acordo com a entrevista de Eduardo Henrique Souza Batista (Dudu) ${ }^{7}$, uma das jovens lideranças do Chapéu Mangueira, o baile acontecia onde hoje é a quadra esportiva da comunidade. De acordo com Eduardo Batista, "era uma quadra aberta, totalmente aberta não tinha palco, não tinha nada. Era uma praça mesmo... Era uma praça aberta. As pessoas podiam acessar à vontade. [...] As pessoas que curtiram dizem que foi o melhor baile da cidade do Rio de Janeiro." Vinham pessoas de toda a cidade, de outras cidades, e também muitos turistas. Ainda segundo Eduardo Batista, "foi o primeiro baile que uniu o asfalto e a favela, junto no mesmo lugar - assim, curtindo, né? De uma maneira de entretenimento".

Como nos lembra Facina (2009, p. 6), juridicamente, a repressão ao funk no Rio de Janeiro tem como marco a "CPI municipal do funk", de 1995, cujo objetivo foi "investigar a suposta ligação do funk com o comércio varejista de drogas na cidade”. Já em 1999, instalouse uma CPI estadual, que pretendia, de acordo com seu artigo primeiro "investigar os bailes funk com indícios de violência, drogas e desvio de comportamento do público infantojuvenil". Como resultado, passa-se a cobrar dos realizadores dos bailes uma série de exigências, entre elas a anuência da autoridade policial e a presença de policiais militares durante todo o evento, além de uma infraestrutura fora dos padrões, financeiros e logísticos, para esse tipo de evento, impedindo, na prática a sua realização.

\footnotetext{
${ }^{7}$ Entrevista realizada em 04 de maio de 2015, por Marildo J. Nercolini.
} 
Também cabe destacar, nesse mesmo ano, a Resolução nº 013, da Secretaria de Estado de Segurança, datada em 23 de janeiro de 2007, que, como lembra a pesquisadora Pamela Passos (2016, p. 5), "de maneira geral, trata-se de uma resolução que atribui aos órgãos de segurança pública a função de preservar a ordem na realização de 'eventos culturais, sociais, desportivos, religiosos e quaisquer outros que promovam concentrações de pessoas no Estado do Rio de Janeiro"". Com a tal resolução, "o procedimento para um realizador obter a autorização para seu evento é composto pela entrega de uma série de documentos e formulário, publicados anexos à Resolução aos representantes da Polícia Militar e Polícia Civil do Rio de Janeiro”. Era a pá de cal nos bailes funk, pois a quantidade e o tipo de exigências impossibilitavam a realização dos mesmos.

A chegada das Unidades de Polícias Pacificadoras complicou e muito a situação do funk e dos bailes funk. As UPPs foram implantadas como parte da política de segurança pública do Estado, inicialmente em 2008, no Morro Santa Marta, no bairro de Botafogo, e nos anos seguintes em outras favelas cariocas, atingindo atualmente o número de 38 UPPs, de acordo com dados coletados em seu site oficial. ${ }^{8}$ Essa política está sendo em parte revista, diante da crise e dos desvarios pelos quais passa o Estado e a cidade do Rio de Janeiro, com seus governos inoperantes ou envolvidos em falcatruas nada republicanas. Ao invés de mais e melhores políticas públicas direcionadas a melhorias na educação, saúde, infraestrutura, desenvolvimento sociocultural, enfim, ações que visem ao aprimoramento da democracia e da cidadania, novamente a saída mirabolante encontrada foi substituir a repressão já instituída por mais repressão. Em fevereiro de 2018, o Governo Federal decretou, com aprovação do Congresso Nacional e apoio dos governos locais, Intervenção na Segurança Pública no Rio de Janeiro 9 , colocando como interventor um general militar no comando, autorizando também o uso das Forças Armadas no Estado. Novamente, as favelas e seus cidadãos são o foco da repressão, em ações midiáticas e espetaculosas, para acalmar a "Casa Grande" e os pretensos “cidadãos de bem".

Mas o mundo funk não ficou parado. Cabe destacar nessa luta a criação, em dezembro de 2008, da Associação de Profissionais e Amigos do Funk (APAFunk), articulada por

\footnotetext{
${ }^{8}$ Ver http://www.upprj.com/index.php/historico. Acessado em 20/02/2017.

${ }^{9}$ A intervenção passou a valer a partir 16 de fevereiro de 2018 até 31 de dezembro de 2018. Consultar: https://www12.senado.leg.br/noticias/materias/2018/02/21/publicado-decreto-de-intervencao-na-segurancapublica-do-rio-de-janeiro.
} 


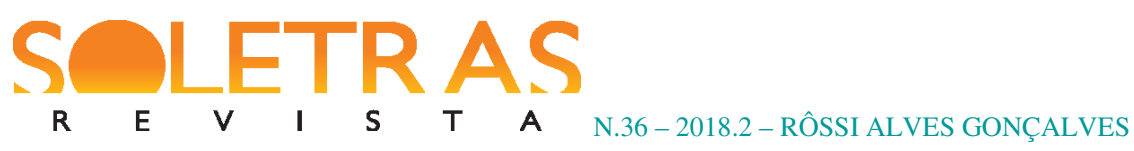

funkeiros e produtores do funk, pesquisadores acadêmicos, advogados e lideranças políticas, que passa a encampar a luta pela criação de uma lei que reconhece o funk como cultura. No ano seguinte, após muita luta e pressão, é aprovada a lei estadual $\mathrm{n}^{\circ} 5543$, promulgada em 22 de setembro de 2009. Também cabe destacar a pressão exercida pelas lideranças do funk que acaba resultando na revogação da resolução 013, em agosto de 2013. Em reportagem do jornal O Dia (2017), MC Leonardo, um dos criadores da APAfunk, festeja a extinção dessa resolução, apontando que políticas públicas como essa "estavam matando a economia das comunidades, os encontros e o direito de se expressar dos moradores".

Essas lutas trouxeram significativos avanços, possibilitando, por exemplo, o edital estadual de "Seleção Pública de Projetos de Bailes e Criação Artística no Funk Chamada Pública n 13", lançado em 2013 pela Secretaria de Estado de Cultura do Rio de Janeiro. Isso possibilitou o retorno de alguns bailes funk como, por exemplo, o da Chatuba e o de Chapéu Mangueira, que voltam a ser realizados em 2015, mas claro que com muitas dificuldades, proibições e após intensos embates com os comandantes das UPPs. No momento as dificuldades se aprofundam novamente, mas a resistência continua.

Mesmo sofrendo muitas e variadas tentativas de proibições e silenciamentos, o funk (e uma de suas principais expressões, o baile funk) continua aí. Seus sujeitos/agentes/agitadores, diante das adversidades, criam táticas para burlar e resistir; gambiarras constantes são engendradas para reinventar o funk, expressão fundamental, como já dito, da cultura urbana carioca. Facina e Lopes (204) nos ajudam a entender esse processo, dando voz a um funkeiro das antigas:

Para MC Leonardo, nascido e criado na Rocinha, as elites combatem e criminalizam o funk de todas as maneiras, pois a briga do funk é antes de tudo uma briga racial. Que ironia! Logo na terra em que governos, mídia corporativa e elites artísticas/intelectuais celebram a democracia racial e a igualdade de "classes, cores e culturas". É impossível pensarmos numa transformação radical da sociedade, se não começarmos a pelo menos reconhecer e respeitar a legitimidade da cultura da juventude negra contemporânea e a dialogar com as suas contradições. Como diz o MC da maior favela da América Latina, "o funk carioca é uma poderosa arma porque é uma forma de comunicação, que mostra o que nós favelados vivemos, pensamos e queremos". 


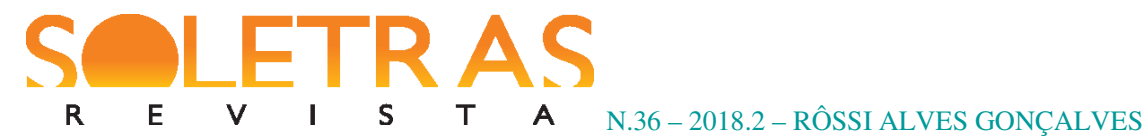

Mesmo que as Rodas de Cultura e os Bailes Funk sejam expressões culturais distintas, conectadas, respectivamente, ao Hip Hop e ao Funk, com suas diferenças e embates, ambas são criações de jovens periféricos em um contexto de cidade que, historicamente, discrimina, criminaliza e desvaloriza a periferia e os sujeitos que nela vivem. Há uma experiência do viver em situação de luta, de "conter-resistir", de criminalização da pobreza e do sujeito negro que une e faz com que os grupos compartilhem as dores e as práticas de conquista. A sigla TMJ - "tamu junto" - vai muito além de uma cordialidade dos que trabalham com cultura de rua, mas evidencia a necessidade de se pensar em modos de sobreviver em contextos tão adversos.

Assim, a união funk/hip hop constrói parcerias em eventos, em clipes de produção coletiva, na agregadora saudação "É o rep, é o funk", do MC PK, entre outras formas de interação. São formas de resistir, re-existir; reinventar-se e reinventar formas de se expressar, de ser ouvido, de ser cidadão.

\section{Referências}

BALLOCO, André. Extinção dos bailes funk deixou 9 mil sem trabalho. O Dia, 18/08/2015. Disponível em http://odia.ig.com.br/noticia/riosemfronteiras/2013-08-19/extincao-dos-bailesfunk-deixou-9-mil-sem-trabalho.html. Acesso: 20/02/2017.

BATISTA, Eduardo. Entrevista realizada por Marildo J. Nercolini, no dia 04 de maio de 2015.

CANCLINI, Néstor G. Culturas híbridas. São Paulo: EDUSP, 1998.

Diferentes, desiguais e desconectados. Rio de Janeiro: Editora da UFRJ, 2005.

CERTEAU, Michel de. A invenção do cotidiano: artes do fazer. Petrópolis, RJ: Vozes, 1998.

DA MATTA, Roberto. A casa e a rua: espaço, cidadania, mulher e morte no Brasil. Rio de Janeiro: Rocco, 1997.

ESCOBAR, Tício. El mito del arte e el mito del pueblo. Buenos Aires: Ariel, 2014.

ESSINGER, Silvio. Batidão: uma história do funk. Rio de Janeiro: Record, 2005.

FACINA, Adriana. "Não me bate doutor": funk e criminalização da pobreza. Anais do $V$ ENECULT, 2009. Disponível em: http://www.cult.ufba.br/enecult2009/19190.pdf. 


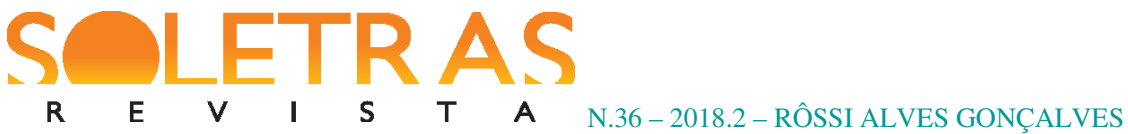

FONTES, Adriana Sansão. Intervenções temporárias, marcas permanentes: apropriações, arte e festa na cidade contemporânea. Rio de Janeiro. Casa da Palavra; FAPERJ, 2013.

FOUCAULT, Michel. Microfísica do poder. Trad. Roberto Machado. Rio de Janeiro: Edições Graal, 1979.

GEERTZ, Clifford. A interpretação das culturas. Rio de Janeiro: LTC, 1989.

HALL, Stuart. Da diáspora: identidades e meditações culturais. Belo Horizonte: Ed. UFMG, 2003.

HERSCHMANN, Micael. O funk e o hip-hop invadem a cena. Rio de Janeiro: Editora UFRJ, 2000.

LOPES, A; FACINA, A. Cidade do funk: expressões da diáspora negra nas favelas cariocas. Revista do Arquivo Geral da Cidade do Rio de Janeiro, n. 6, 2012, p. 193-206.

LOPES, Adriana Carvalho. "Funk-se quem quiser": no batidão negro da cidade carioca. Campinas, SP: Unicamp, 2010 (Tese de Doutorado).

LUDMER, Josefina. Literaturas pós-autônomas. Sopro 20, Desterro, janeiro de 2010. Disponível em: www.culturaebarbarie.org/sopro.

MESQUITA, André Luiz. Insurgências poéticas: arte ativista e ação coletiva (1990-2000). Dissertação (Mestrado). USP. São Paulo, 2008.

MOUFFE, Chantal. Artistic Activism and Agonistic Spaces. Art \& Research, a journal of ideas, contexts and methods, v. 1, n. 2, London, 2007.

NOVAES, Dennis. Funk Proibidão: música e poder nas favelas cariocas. Dissertação de mestrado - Universidade Federal do Rio de Janeiro, Museu Nacional, Programa de PósGraduação em Antropologia Social, 2016.

PASSOS, Pamela; ROSA, Sandro H. Funk carioca e políticas públicas de cultura: avanços e retrocessos entre 2008 e 2016. Salvador, Anais do XII ENECULT, 2016, p. 1-14. http://www.cult.ufba.br/enecult/2894-2/.

SANTOS, Milton. Território e sociedade: entrevista com Milton Santos. São Paulo: Editora Perseu Abramo, 1996.

Por uma outra globalização. Rio de Janeiro: Record, 2000.

VIANNA, Hermano. O mundo funk carioca. Rio de Janeiro: Jorge Zahar, 1988.

p. 244-253.

Funk e cultura popular carioca. Estudos Históricos, Rio de Janeiro, v. 3, n. 6, 1990, 


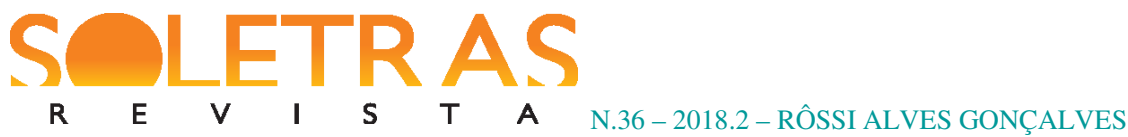

WILLIAMS, Raymond. Base e superestrutura na teoria cultural marxista. Revista da USP, São Paulo, n. 65, p. 210-224, mar./mai. 2005.

\title{
The peripheral urban culture: silences and tactics
}

\begin{abstract}
In this article we propose to analyze two fundamental manifestations of the urban art of the city of Rio de Janeiro, understanding them as anti-canonical narratives of the city the Cultural Circles and the "Bailes Funk" (funk parties), produced by individuals coming from the peripheries of Rio. We will aim at reflecting upon the constant difficulties imposed by the public power to carry out these interventions, as well as detecting and analyzing the tactics used by those individuals to overcome these difficulties and put their art into circulation. In Rio, the silencing of these expressions is due to the prohibition of "Bailes Funk" in the slums and by the repression to the occupation of the public space by the Cultural Circles. However, as the field of culture is a process, such a situation of silencing is not fixed: if there are symbolic and real boundaries that restrict the artistic achievement of these young people, those boundaries also produce counter-narratives in which the innovative ways of creating art in context of criminalization become explicit. The action of these peripheral individuals has brought to the Rio cultural scene exchanges, hybridity, varied experiments that find on the blocks, streets and squares a place of welcome.
\end{abstract}

Key-words: Urban art in Rio. Narratives. Repression. Resistances.

Recebido em: 26 de maio de 2018.

Aceito em: 30 de julho de 2018. 